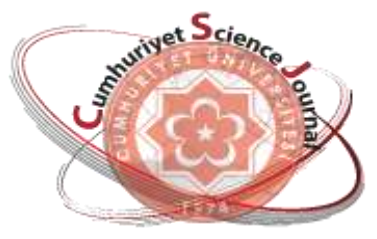

e-ISSN: $2587-246 X$

ISSN: $2587-2680$

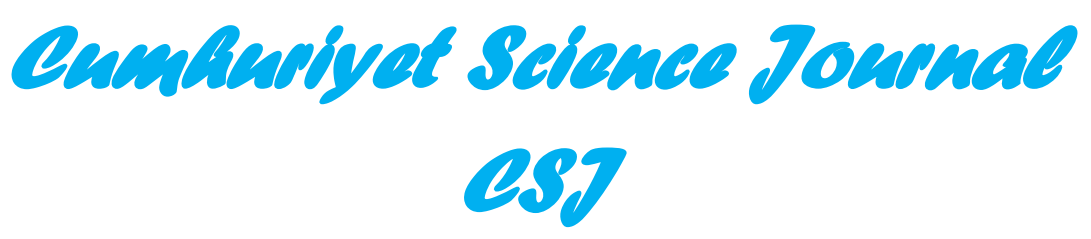

Cumhuriyet Sci. J., Vol.39-1(2018) 294-302

\title{
Analysis and Extraction of Fetal Electrocardiogram Signal with Adaptive Filtering Using Differential Evolution Algorithm
}

\author{
Serdar KOCKANAT ${ }^{1}$, Serkan KOCKANAT ${ }^{2}$ \\ ${ }^{I}$ Cumhuriyet University, Faculty of Engineering, Department of Electrical and Electronics Engineering, Sivas, TURKEY \\ ${ }^{2}$ Republic of Turkey Ministry of Health, Sivas Numune Hospital, Department of Emergency Service, Sivas, TURKEY \\ Received: 17.07.2017; Accepted: 26.12.2017 \\ http://dx.doi.org/10.17776/csj.407424
}

\begin{abstract}
Recent studies have demonstrated the advantages of fetal electrocardiogram (ECG) extraction and analysis. In this study, a new approach is proposed for fetal ECG signal extraction using differential evolution algorithm and adaptive filtering. The results obtained by the proposed approach are compared with the result of the adaptive method based on the least mean square method in the literature. According to the obtained results, the proposed approach gives better results in terms of fetal ECG signal extraction.
\end{abstract}

Keywords: Electrocardiogram, fetal, adaptive filter, evolution algorithm

\section{Diferansiyel Gelişim Algoritması Kullanılarak Adaptif Süzgeçleme ile Fetal Elektrokardiyogram İşaretinin Çıkarılması ve İncelenmesi}

\begin{abstract}
Özet: Son yıllarda yapılan çalışmalar fetal elektrokardiyogram (ECG) işaretinin elde edilmesinin ve incelenmesinin sağladığı avantajları göstermektedir. Bu çalışmada, diferansiyel gelişim algoritması ve adaptif süzgeçleme kullanılarak fetal EKG işaretinin çıkarımı için yeni bir yaklaşım önerilmiştir. Önerilen yaklaşım ile elde edilen sonuçlar literatürde en küçük ortalama kareler metoduna dayanan adaptif metodun sonucu ile karşılaştırılmıştır. Elde edilen sonuçlara göre önerilen yaklaşım fetal EKG işaretini elde etme açısından daha iyi sonuç vermektedir.
\end{abstract}

Anahtar Kelimeler: Elektrokardiyogram, cenin, adaptif süzgeç, evrimsel algoritma

\section{INTRODUCTION}

In recent years, depending on the developing electronic and biomedical technologies, analyzing the healthy functioning of the heart, which is one of our most important organs, and diagnosing its diseases are an important issue for researchers. Electrocardiography (ECG) signal is an electrical signal that is generated by heart and contains useful information about all of heart's activities [1]. In addition, the ECG signal is a biomedical signal that facilitates diagnosis and follow-up of specialists in a wide range of age groups, from children to adults.

Particularly research studies in the last 20 years, examination and diagnosis of fetal heart electrical activity in mother's womb is possible with fetal

\footnotetext{
* Corresponding author. Email address: skockanat@ cumhuriyet.edu.tr http://dergipark.gov.tr/csj C2016 Faculty of Science, Cumhuriyet University
} 
electrocardiography. Fetal ECG provides meaningful information about the physiological state of the fetus and it is also beneficial for medical specialists to make correct and appropriate decisions during the medical examination. Also, fetal mortality rates can be reduced by monitoring fetal cardiac activities [2, $3]$. So, when the medical reports in recent years are examined, one out of 125 babies is born with heart defects that can even cause death [4]. Today, several different methods are used to examine fetal heart activity. One of the most preferred methods is echocardiography that allows examining mechanical heart activities. However, fetal ECG method is simpler and easier than other methods. Compared to other methods based on heart rate and heart sound, it is more effective in detecting fetal ECG abnormalities and has no negative effects on the mother or the fetus. In the light of these advantages, extraction and analysis of a fetal ECG signal that is meaningful and free of disruptive effects have become an important issue on the following of fetal health and its cardiac activity $[5,6]$.

Although the fetal ECG signal is so important for fetal health and preliminary diagnosis, it is more difficult and complicated to obtain noise free and meaningful ECG signal. The fetal ECG signal is extracted from the maternal ECG signals which are obtained from the ECG device connected to the abdominal and thoracic region of the pregnant woman. However, the fetal ECG signal is so weak against the maternal ECG signal and affected by the influences of many disturbing signals such as muscle noise, power line pollution [7, 8]. In Figure 1, a general process diagram is showed for acquisition, processing and extraction of fetal ECG signal $[3,9]$.

According to Figure 1, maternal ECG signals are acquired from the probes connected to the abdominal and thoracic regions of the pregnant woman by using the ECG device and acquisition step is successively realized. Then, these obtained ECG signals are processed by computer and fetal ECG signal is extracted and analyzed. The general steps can be briefly represented and in the following sections, an extended discussion about this steps will be made.

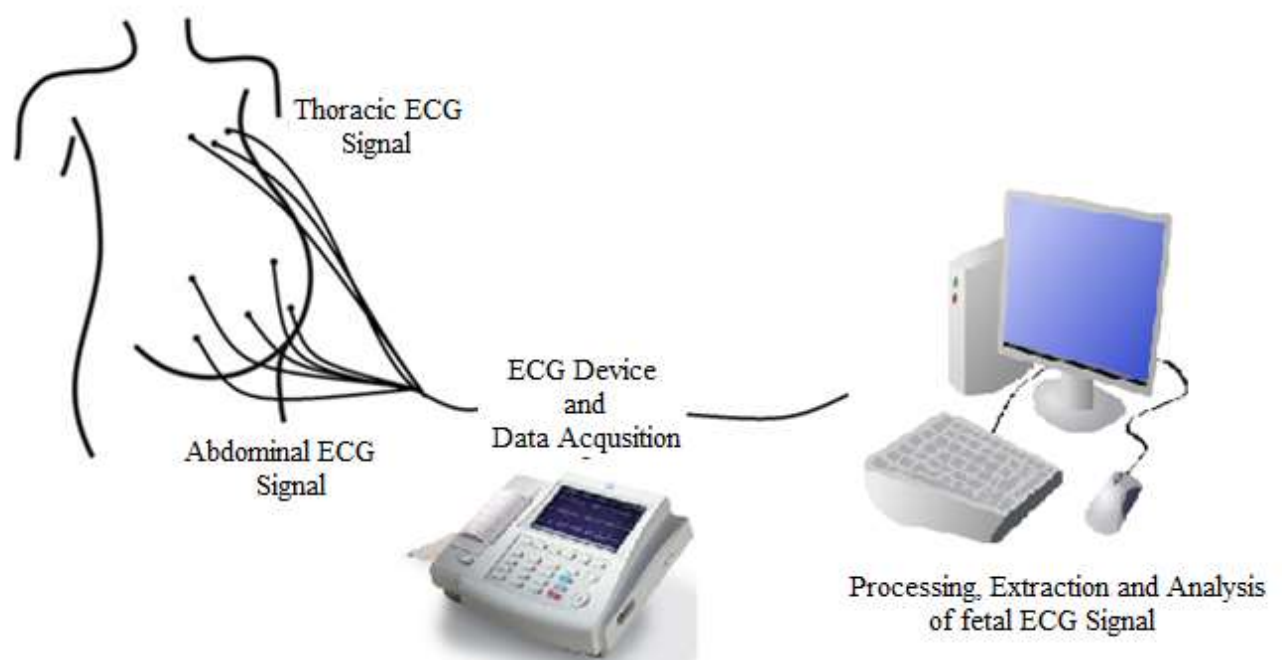

Figure 1. General steps for acquisition, extraction and analysis of fetal ECG signal. 
Several methods for processing and extraction of fetal ECG signals have been proposed in the literature [10]. Adaptive filtering [3, 11], single value decomposition (SVD) method [12], artificial neural network (ANN) [13], wavelet transform [14], kalman filter [15], fuzzy logic approach [16] and independent component analysis $[17,18]$ are most suggested studies in literature. Each method proposed in the literature has some advantages and disadvantages. For example, there are different difficulties and complexities problems such as non-convergence or function selection of network structures in artificial neural networks, complexity of statistical modeling of probability distribution functions in independent component analysis or unwanted distortions in the adaptive filtering.

In this study, it is aimed to extract and analyze the fetal ECG signal that informs about fetal cardiac activities from the maternal ECG signals obtained from the thoracic and abdominal region of the pregnant woman. For this purpose, a differential evolution (DE) algorithm, which is used effectively in the solution of optimization problems in many scientific fields such as medicine, electronics, construction and industry, is combined with adaptive filtering. A combined method is proposed and aimed to effectively extract fetal ECG signal. The results obtained by the proposed approach are compared with the results obtained by adaptive least mean squares (LMS) method in the literature and their performance is evaluated.

In addition, the explanation plan of this paper has been organized as follows. In Chapter 2, differential evolution algorithm and its basic steps are explained. In Chapter 3, fetal ECG extraction steps and clinical experimental data collection are described. The achieved results with the proposed approach are demonstrated and compared in Chapter 4. In Chapter 5, comments and discussion are given.

\section{DIFFERENTIAL EVOLUTION ALGORITHM}

The differential evolution (DE) algorithm is a population-based metaheuristic algorithm in the class of evolutionary algorithms and proposed by Storn and Price in 1997 [19]. It has standard operators such as mutation, crossover and selection. The difference of the DE algorithm from the other evolutionary algorithms which have the same operators, is based on applying a mutation operation that uses the difference of randomly chosen solutions while applying each operator to the whole population in order to obtain better solutions. Through mutation and crossover operators, three randomly selected chromosomes are selected and new individuals are created. By comparing the fitness values of the new chromosome and the existing chromosome, the individual with better fitness is transferred to the next population as the new individual. The selection operator is also used here. In addition, the basic control parameters controlling the performance of the DE algorithm can be expressed as population size, scaling factor $(F)$, crossover rate $(C R)$, and maximum number of cycles. The basic steps of the DE algorithm can be given as follows.

Step 1: Generate population according to initial values

Step 2: Evaluate population using objective function

Step 3: repeat

Step 4: Apply the mutation operator

Step 5: Apply the recombination operator

Step 6: Evaluate population using objective function

Step 7: Apply the selection operator

Step 8: until (cycle = maximum cycle number) 


\section{THE PROBLEM of FETAL ECG EXTRACTION}

The problem of fetal ECG extraction has been studied and improved in two stages. At the first stage, DE algorithm and adaptive filtering were combined in harmony and a combined approach was developed to ensure that the desired fetal ECG signal is obtained quickly and efficiently. At the second step, the acquisition of clinical experimental data was performed to use in the proposed approach.

\subsection{Integration of Adaptive Filtering and DE Algorithm}

In Figure 2, a block diagram shows integrating and applying the adaptive filtering and $\mathrm{DE}$ algorithm. As can be seen from this figure, the proposed ECG extraction system has two inputs, one output and one feedback. $d(n)$ is the primary input signal (Abdominal ECG Signal) and represents the maternal ECG signals from the abdominal region. Also, $x(n)$ is the second input signal (Thoracic ECG Signal) and shows the maternal ECG signals from the thoracic region. $y(n)$ is the adaptive filter output. In Figure 2, a finite impulse response (FIR) digital filter is employed in adaptive filtering process and its formula is given as

$$
y(n)=\sum_{k=0}^{K-1} w x(n-k)
$$

Here, the input signal $x(n)$, the output signal $y(n)$ , the degree of the digital filter $K$, and the filter coefficient vector $w$ are shown. $w=\left[b_{0} b_{1} b_{2} \ldots b_{n}\right]$ presents coefficients vector of FIR digital filter. $e(n)$ is the feedback signal (Fetal ECG Signal) and it feeds the DE algorithm using equation $e(n)=d(n)-y(n)$. Also, it assists the algorithm to optimize the coefficient vector of the adaptive filter. DE algorithm uses the error signal $e(n)$ to minimize the objective function that is represented as

$$
J=\min \left(\sum_{n=1}^{N}(d(n)-y(n))^{2}\right)=\min \left(\sum_{n=1}^{N} e_{n}^{2}(n)\right)=\operatorname{MSE}(d(n)-y(n))
$$

In this case, depending on the objective function, it evaluates the coefficients vector of the adaptive filter through the mutation, crossover and selection operators and tries to extract the best fetal ECG output signal.

The aim the block scheme in figure 2 is to obtain the fetal ECG signal, which is the difference between the two input signals, by adaptive filtering and at the same time, the smoothest fetal ECG signal is quickly transferred to the output by optimizing coefficients vector of the adaptive filter using DE algorithm.

For the performance improvement of the $\mathrm{DE}$ algorithm, population size of 20 , a scaling factor $(F)$ of 0.5 , a crossover ratio $(C R)$ of 0.9 and a maximum number of cycles of 500 were experimentally selected. DE algorithm was run 50 times with different initial values and the best results were evaluated. Furthermore, in the adaptive filter structure, a 7 th-order finite impulse response digital filter was applied. 


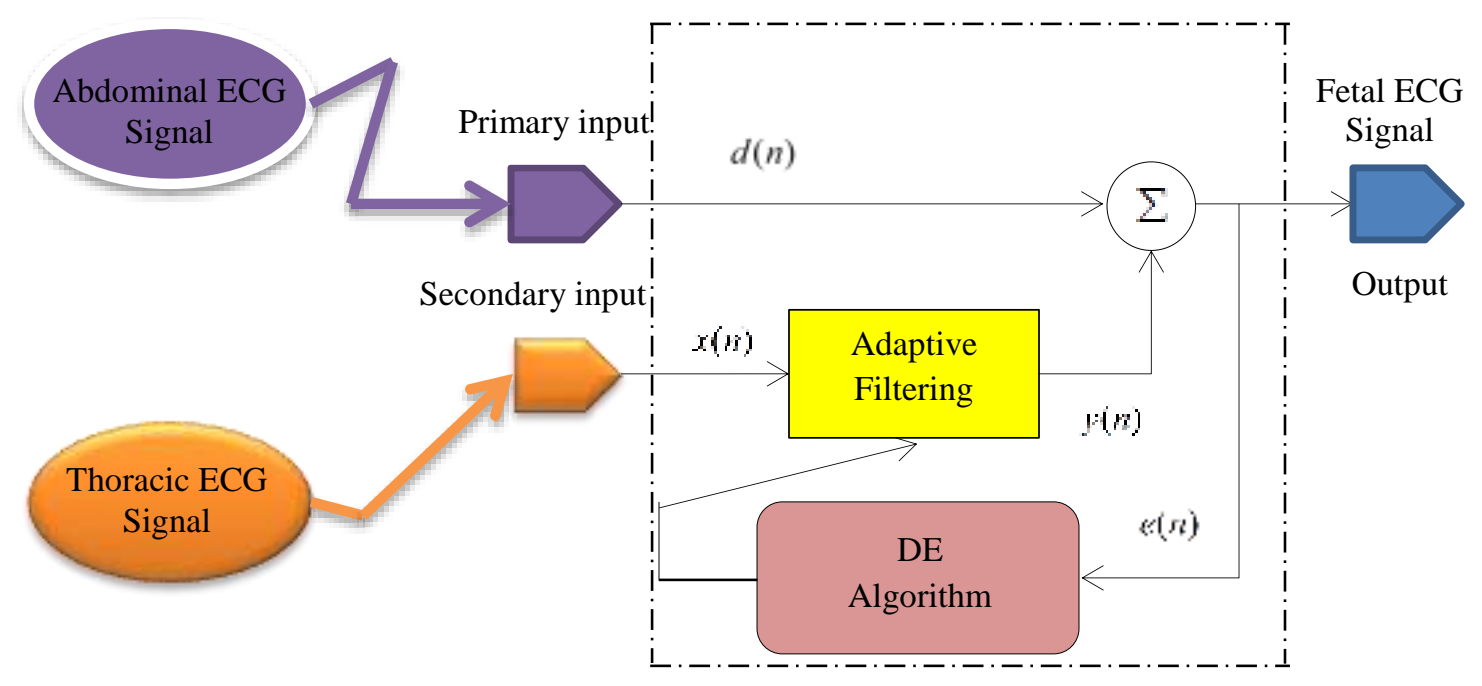

Figure 2. Block diagram for combining and applying DE algorithm with adaptive filtering.

\subsection{Clinical Data Acquisition}

In this study, clinical ECG signals have been used to extract the fetal ECG signal. These clinical signals were derived from a database which is called Daisy (Database for the identification of Systems) and formed by Lathauwer [20]. Clinical signals in Daisy database were obtained from a pregnant woman as using 8 channel probes. 8 channel signals consist of 5 abdominal signals and 3 thoracic signals. Clinical signals were sampled with a sampling frequency of $250 \mathrm{~Hz}$ and recorded for 10 seconds. Channels 1, 3 and 5 for the abdominal region and channels 6 and 8 for the thoracic region have been used since the data from some channels are not stable. Each ECG signal includes 2500 sample points and all points were applied in the proposed method. But, 1000 sample points have been shown for easy understanding of graphics.

\section{CONCLUSION and ANALYSIS}

Figure 3 shows 8-channel maternal ECG signals from the DaISy database. Channel 1-5 shows the
ECG signals from the abdominal region, and channels 6-8 show the ECG signals from the thoracic region.

In Figure 4, the results of the least mean squares (LMS) method, which is previously suggested for fetal ECG extraction in the literature, are presented [3]. Here, the first and 8th channels are used for the abdominal and thoracic regions, respectively. In Figure 4, markings on the fetal ECG signal obtained by the LMS method demonstrate disorders that causes loss of meaningful information about cardiac activity. Although the LMS method provides a quick solution to extract the fetal ECG signal, the occurred distortions on the waveforms affect negatively the performance and it can cause the loss of meaningful information in the fetal ECG signal.

In Figure 5, the extracted fetal ECG signal obtained by the proposed approach is shown. Although both suggested methods use same channels 1 and 8, the distortions occurring in Figure 4 are not observed on the obtained fetal ECG signal in Figure 5. Also, in Figure 5, the fetal ECG signal is efficiently and quickly obtained 
with the proposed approach and the distortions in the LMS method are eliminated. In addition, when the fetal ECG signal in Figure 5 is examined, it is observed that the $\mathrm{R}$ peaks belonging to the QRS wave are prominent and the heart rate can be easily determined from the ECG signal using appropriate techniques.
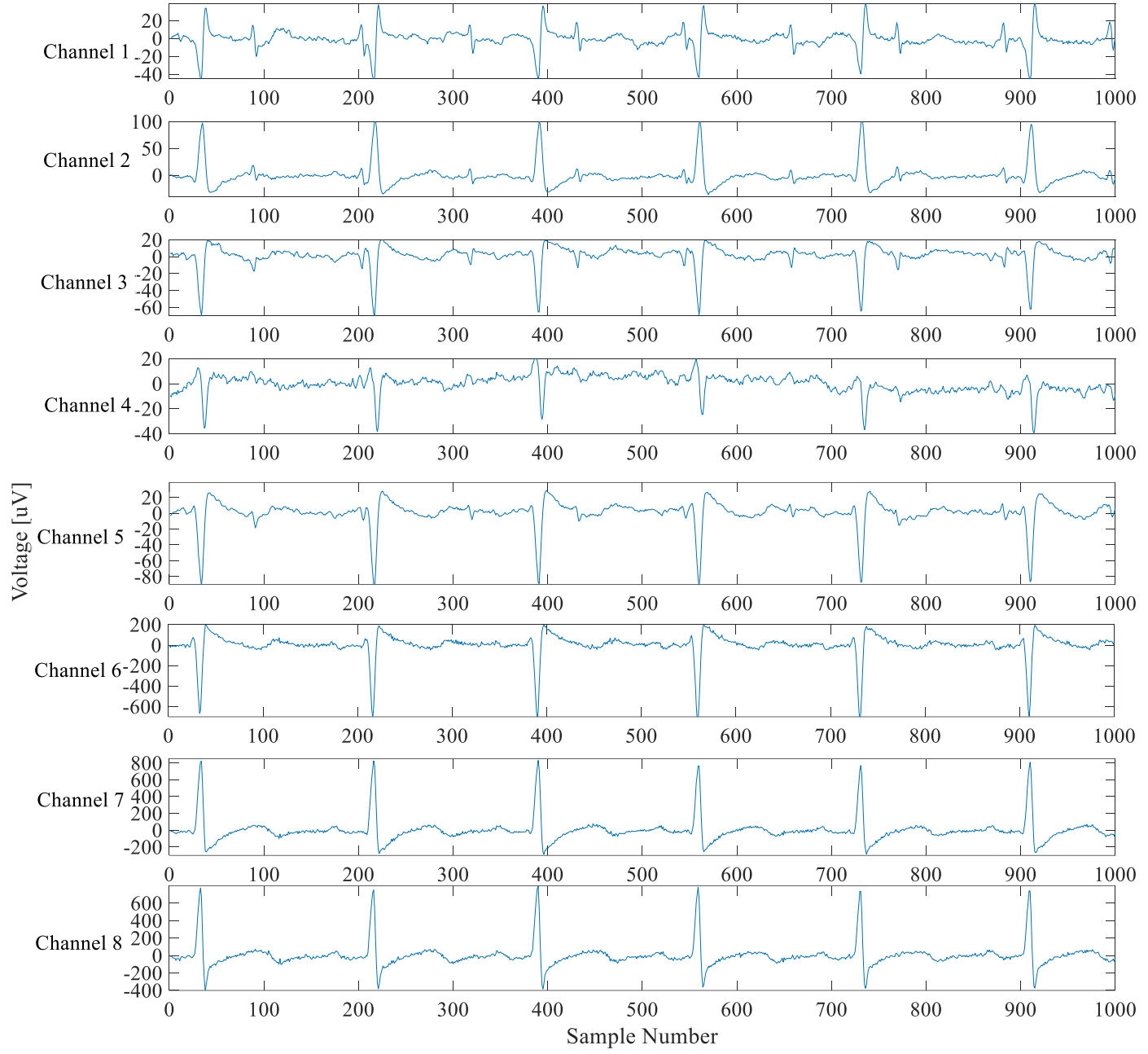

Figure 3. 8 channel ECG signal for pregnant woman (Channel 1-5 abdominal, Channel 6-8 thoracic). 


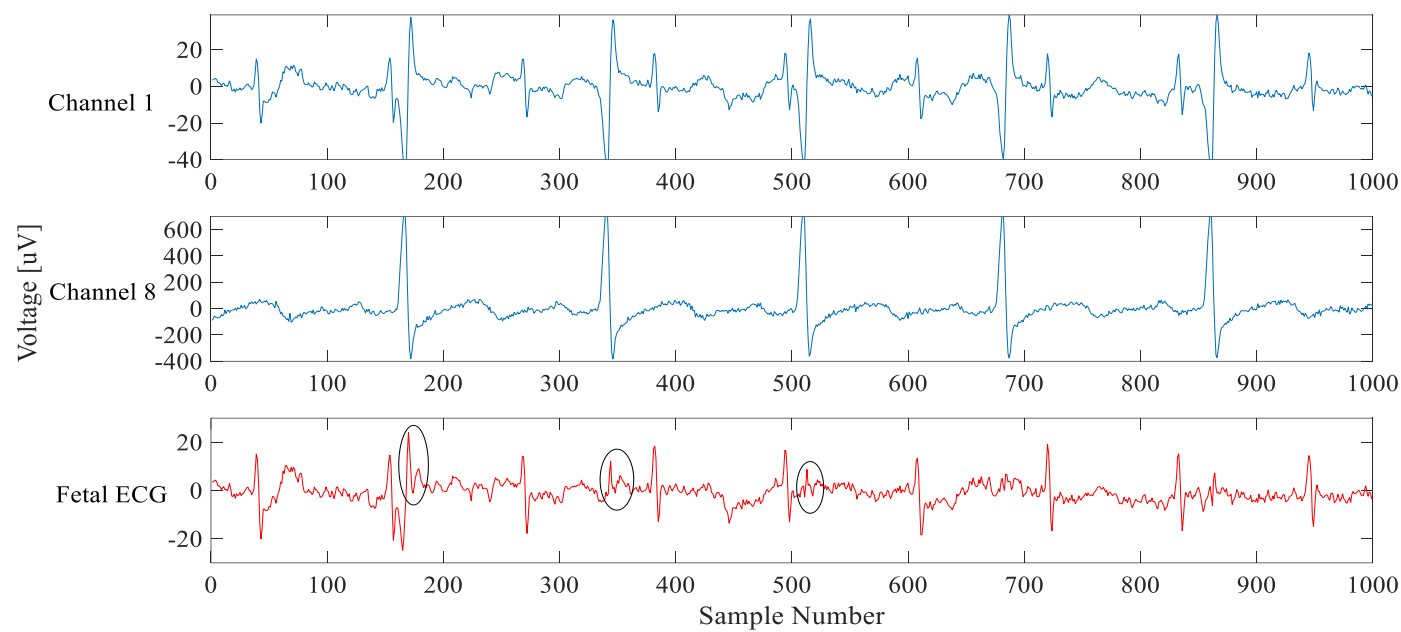

Figure 4. Fetal ECG signal obtained by least mean squares (LMS) method.

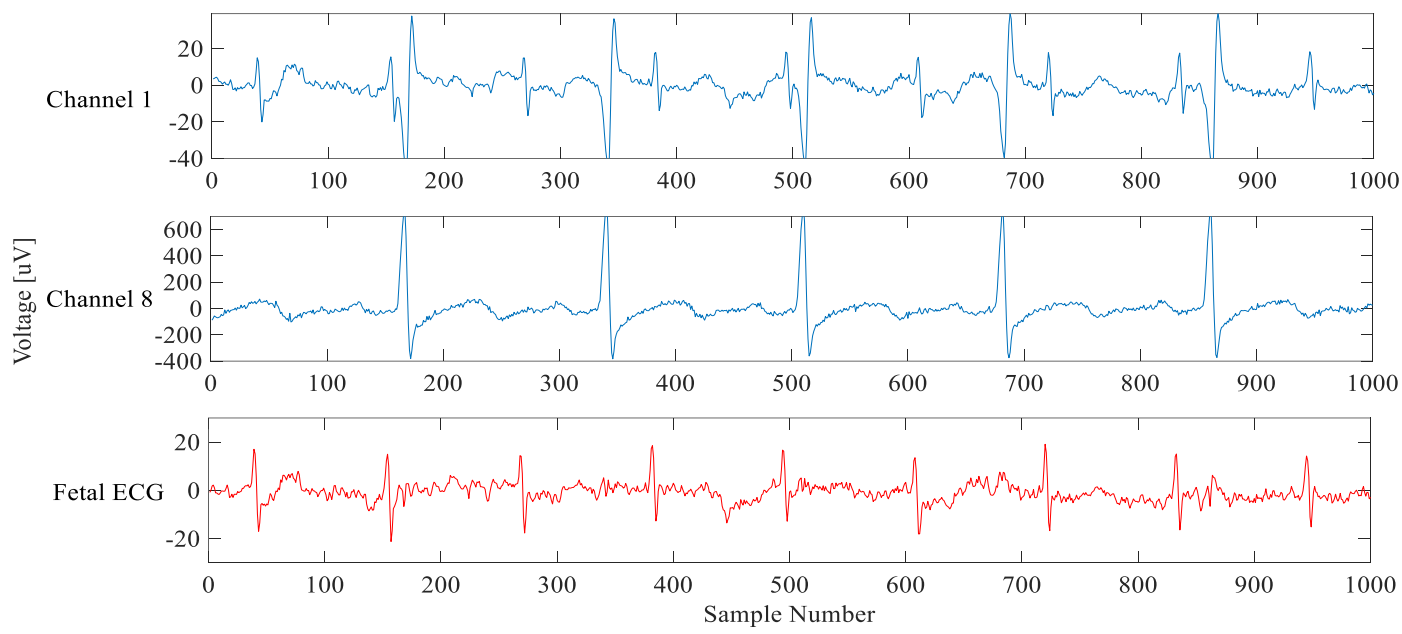

Figure 5. Fetal ECG signal obtained by the proposed approach combining the DE algorithm with adaptive filtering. 


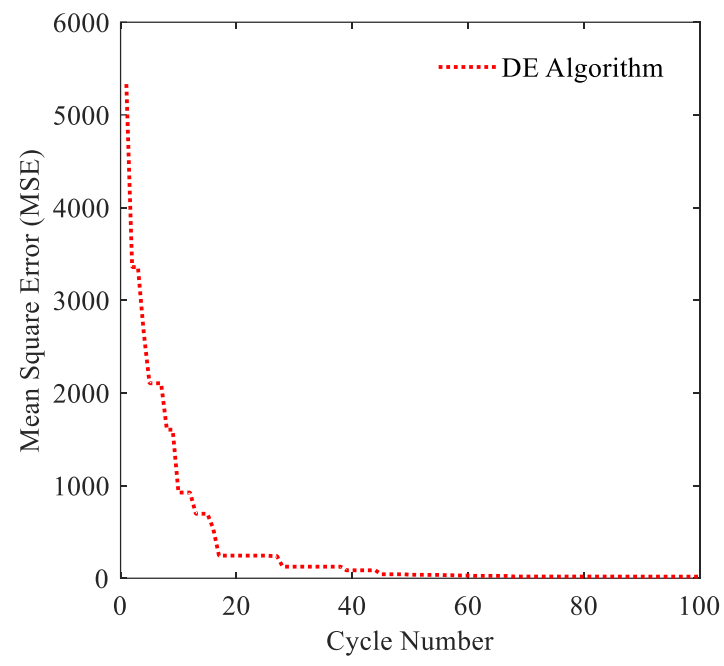

Figure 6. Error convergence of the proposed approach.

Figure 6 shows the error convergence of the proposed approach. Although the maximum cycle number of the DE algorithm is selected as 500, the algorithm approaches to the minimum values without reaching 100 cycles. This shows the fast and efficient convergence of the proposed method.

For the multiple runs of the DE algorithm, the average error is calculated as 20.6091, the standard deviation value is 4.4943 and the best value is 17.0460. In addition, coefficients of the 7th order finite impulse response digital filter used in adaptive filtering are given in Table 1 depending on the best error value. Also, the MSE value of the proposed LMS algorithm is computed as 18.9137. This value shows that the MSE value of the proposed DE algorithm is smaller and its performance is about $10 \%$ better than those of the other algorithm.

Table 1. The coefficients of the 7th order finite impulse response digital filter.

\begin{tabular}{c|c|c|c|c|c|c|c}
\hline \multicolumn{1}{c}{ Coefficients } \\
\hline$b_{0}$ & $b_{1}$ & $b_{2}$ & $b_{3}$ & $b_{4}$ & $b_{5}$ & $b_{6}$ & $b_{7}$ \\
\hline-0.0388 & -0.0195 & -0.0149 & 0.0074 & 0.0062 & 0.0034 & 0.0017 & 0.0058 \\
\hline
\end{tabular}

\section{DISCUSSION and CONCLUSION}

In this study, for fetal ECG extraction, a new adaptive approach is proposed combining DE algorithm with adaptive filtering. The actual clinical data were used to assess the performance of the proposed approach and the obtained results were compared with those of the literature. Accordingly, the approach using a metaheuristic algorithm showed better performance than the ones using classical algorithms.

In addition, the fetal ECG signal obtained by the $\mathrm{DE}$ algorithm based approach is an appropriate signal to extract important data such as heart beat. However, the R peaks of the fetal ECG signal are quite clear. In the future studies, the proposed method will be realized as hardware and a real- time fetal ECG acquisition system will be designed and the results will be shared with the literature.

\section{REFERENCES}

[1]. Barold S.S. Willem Einthoven and the Birth of Clinical Electrocardiography a Hundred Years Ago. Cardiac Electrophysiology Review, 7 (2003) 99104.

[2]. Jia W., Yang C., Zhong G., Zhou M., Wu S. Fetal ECG extraction based on adaptive linear neural network. In:3rd International Conference on Biomedical Engineering and Informatics, Yantai, China,16-18 October 2010, pp.889-902. 
[3]. Wu S., Shen Y., Zhou Z., Lin L., Zeng Y., Gao X. Research of fetal ECG extraction using wavelet analysis and adaptive filtering. Computers in Biology and Medicine, 43 (2013) 1622-7.

[4]. Congenital Heart Defects in Children Fact Sheet, American Heart Association 2008. [Online]. Available: http://www.americanheart.org/children.

[5]. Lathauwer L.D., Moor B.D., Vandewalle J. Fetal electrocardiogram extraction by blind source subspace separation. IEEE Trans. Biomed. Eng., 47 (2000) 567-572.

[6]. Ahmadieh H., Asl B.M. Fetal ECG extraction via Type-2 adaptive neuro-fuzzy inference systems. Computer Methods and Programs in Biomedicine, 142 (2017) 1018.

[7]. Poungponsri S., Yu X-H. An adaptive filtering approach for electrocardiogram (ECG) signal noise reduction using neural networks. Neurocomputing, 117 (2013) 206-13.

[8]. Wei Z., Xueyun W., Jian ZJ., Hongxing L. Noninvasive fetal ECG estimation using adaptive comb filter. Computer Methods and Programs in Biomedicine, 112 (2013) 125-34.

[9]. Martinek R., Kahankova R., Nazeran H., Konency J., Jezewski J., Janku P., Bilik P., Zidek J., Nedoma J., Fajkus M. NonInvasive Fetal Monitoring: A Maternal Surface ECG Electrode Placement-Based Novel Approach for Optimization of Adaptive Filter Control Parameters Using the LMS and RLS Algorithms. Sensors, 17 (2017) 1-31.

[10]. Jagannath D.J., Selvakumar A.I., Issues and research on foetal electrocardiogram signal elicitation. Biomedical Signal Processing and Control, 10 (2014) 224-44.

[11]. Puthusserypady S., Extraction of fetal electrocardiogram using H(infinity) adaptive algorithms. Med. Biol. Eng. Comput., 45 (2007) 927-937.

[12]. Al-Zaben A., Al-Smadi A. Extraction of foetal ECG by combination of singular value decomposition and neuro-fuzzy inference system. Phys. Med. Biol., 51 (2006) 137-143.

[13]. Camps-Valls G., Martínez-Sober M., Soria-Olivas E., Magdalena-Benedito R., Calpe-Maravilla J., Guerrero-Martínez J. Foetal ECG recovery using dynamic neural networks. Artif. Intell. Med., 31 (2004) 197-209.

[14]. Khamene A., Negahdaripour Sh. A new method for the extraction of fetal ECG from the composite abdominal signal. IEEE Trans. Biomed. Eng., 47 (2000) 507516.

[15]. Niknazar M., Rivet B., Jutten C. Fetal ECG extraction by extended state Kalman filtering based on single-channel recordings IEEE Trans. Biomed. Eng., 60 (2013) 1345-1352.

[16]. Assaleh K., Extraction of fetal electrocardiogram using adaptive neurofuzzy inference systems. IEEE Trans. Biomed. Eng., 54 (2007) 59-68.

[17]. Senim Y., Atasoy A., Performance evaluation of nonparametric ICA algorithm for fetal ECG extraction. Turk. J. Electr. Eng. Comput. Sci., 19 (2011) 657-666.

[18]. Najafabadi F.S., Zahedi E., Mohd Ali M.A., Fetal heart rate monitoring based on independent component analysis. Comput. Biol. Med., 36 (2006) 241-252.

[19]. Storn R., Price K., Differential Evolution A simple and efficient heuristic for global optimization over continuous spaces. J. Global Optim., 11 (1997) 341-359.

[20]. Lathauwer L., Daisy: Database for the Identification of Systems: Biomedical Systems. http://homes.esat.kuleuven.be/ s mc/daisy, 2000-10-10/2011-3-8. 